\title{
The dysmorphic cervical spine in Klippel-Feil syndrome: interpretations from developmental biology
}

\section{Karoly M. David, M.D., Peter V. Thorogood, Ph.D., John M. Stevens, F.R.C.R., and H. Alan Crockard, F.R.C.S.}

Departments of Surgical Neurology and Neuroradiology, The National Hospital for Neurology and Neurosurgery, London, United Kingdom; and Developmental Biology Unit, Institute of Child Health, University of London, London, United Kingdom

The authors conducted a study to identify radiological patterns of Klippel-Feil syndrome (KFS), and they present a new interpretation of the origin of these patterns based on recent advances in understanding of embryonic development of the spine and its molecular genetic control.

The authors studied radiographs and computerized tomography (CT) scans as well as magnetic resonance images or CT myelograms obtained in 30 patients with KFS who were referred for treatment between 1982 and 1996; the patients had complained of various neuroorthopedic complications. Homeotic transformation due to mutations or disturbed expression of Hox genes is a possible mechanism responsible for $\mathrm{C}-1$ assimilation, which was found to have occurred in 19 cases (63\%). Notochordal defects and/or signaling problems, which result in reduced or impaired Pax-1 gene expression, may underlie vertebral fusions. This, together with asymmetrical distribution of paraxial mesoderm cells and a possible lack of communication across the embryonic midline, could cause asymmetrical fusion patterns, which were present in 17 cases (57\%). The wide and flattened shape of the fused vertebral bodies and their resemblance to the embryonic cartilaginous vertebrae as well as the process of progressive bone fusion with age suggest that the fusions occur before or, at the latest, during chondrification of vertebrae.

The authors suggest that the aforementioned mechanisms are likely to be, at least in part, responsible for the observed patterns in KFS that affect the craniovertebral junction and the cervical spine.

Key Words * Klippel-Feil syndrome * craniovertebral anomaly * segmentation * Hox gene * Pax gene * asymmetry

The authors of recent molecular studies used to investigate transgenic mice and naturally occurring mutant mouse strains to elucidate the genetic specification of the mammalian body plan, including the axial skeleton, have identified a number of developmental control genes and their roles in segmentation. The dramatic demonstration of not only gene conservation but functional conservation between various animal model systems and humans, exemplified by the discovery of the "master gene" role for the Pax-6 gene in eye development,[43] underscores that these studies can provide unique insights into congenital malformation.[56] In our report we argue that new knowledge emerging from animal studies about the genetic control of the formation of the axial skeleton can potentially provide new paradigms to explain some of the segmentation defects that characterize certain dysmorphic syndromes. To illustrate this contention we focus on one particular syndrome, Klippel-Feil syndrome (KFS), which is characterized by a diversity of segmentation defects. Thus, the aim of this paper, after providing a brief review of 
the KFS phenotype and the characteristic radiological patterns of the cervical spine and craniovertebral junction, is to interpret, or reinterpret, these features in the light of current developmental biology. To illustrate how this knowledge might be used to understand the dysmorphology of KFS we speculate on how the normal morphogenetic mechanisms (and particularly their genetic control) can be perturbed to generate some of the more common features of KFS in the cervical spine and craniovertebral junction.

In 1912, Maurice Klippel and André Feil described an autopsy finding of extensive cervical and thoracic vertebral fusions in a 46-year-old tailor with low posterior hairline, restriction of neck movements, and short neck.[29] Today, the term Klippel-Feil syndrome identifies a phenotype in which failure of segmentation in the cervical spine has occurred, although the classic clinical triad is only present in approximately half of the cases in which cervical fusion has occurred.[21,22] The incidence of the syndrome has been estimated to be one in 42,000 individuals.[20] Klippel-Feil syndrome usually occurs in conjunction with a number of different anomalies, the frequency of which largely depends on patient selection. The most common abnormalities associated with KFS are skeletal anomalies (such as Sprengel's deformity, basilar invagination, skull asymmetry, and scoliosis), hearing impairment, congenital heart diseases, ocular malformations, cranial and facial asymmetry, cleft palate, $[21,37,38]$ genitourinary malformations,[45] and mirror movements.[22,50,62] Other rare associations reported to occur in conjunction with KFS include partially or completely split cervical cord,[9] anomalous rib,[48] neurenteric cyst,[61] neurenteric fistula that causes recurrent meningitis,[19] and dermoid cyst.[12,47] The exact causes of KFS are unknown, although genetic factors for C2-3 (autosomal dominant) and C5-6 (autosomal recessive) fusions have been suggested,[20] and environmental factors such as alcohol consumption may also have a role.[49]

\section{CLINICAL MATERIAL AND METHODS}

We reviewed the common radiological features of the cervical spine that were identified in a sample group of 30 patients with KFS and various neuroorthopedic complaints who were referred to the authors between 1982 and 1996. Radiographs and computerized tomography (CT) scans as well as magnetic resonance (MR) images or CT myelograms were carefully analyzed to identify radiological patterns of the malformation. Special attention was given to fusion patterns including asymmetry, progression of bone fusion with age, and the shape of the fused vertebral bodies. The patient population consisted of 16 males and 14 females with a mean age at the time of the clinical presentation of 19.3 years (range 2 months- 66 years). Details of the patient population, including levels of fusion, presence of left-right asymmetrical fusion, presenting symptoms, clinical and radiological features, associated anomalies, and family history are summarized in Table 1. 


\begin{tabular}{|c|c|c|c|c|c|c|c|c|}
\hline $\begin{array}{l}\text { Case } \\
\text { No. }\end{array}$ & $\underset{\text { Sex }}{\text { Age }[y s]}$ & $\begin{array}{l}\text { Fusion } \\
\text { Levels }\end{array}$ & $\begin{array}{l}\text { Asym- } \\
\text { metry }\end{array}$ & $\begin{array}{l}\text { Presenting } \\
\text { Symptoms }\end{array}$ & $\begin{array}{l}\text { Clirical } \\
\text { Features }\end{array}$ & $\begin{array}{l}\text { Raddogical } \\
\text { Features }\end{array}$ & $\begin{array}{l}\text { Associated } \\
\text { Anomali es }\end{array}$ & $\begin{array}{l}\text { Family } \\
\text { History }\end{array}$ \\
\hline 1 & $0.2, \mathrm{~F}$ & $\mathrm{C} 2-\mathrm{T} 5$ & yes & $\begin{array}{l}\text { poor respiration, } \\
\text { in tubated \& wen- } \\
\text { tilated at tirth; } \\
\text { deformed SN }\end{array}$ & $\begin{array}{l}\text { SN, low hairline, } \\
\text { RNM, Sprengel's } \\
\text { deformity }\end{array}$ & $\begin{array}{l}\text { VF, prominent It }-\mathrm{tt} \\
\text { ossification, ant } \\
\text { midsagittal bone } \\
\text { defect at } \mathrm{C}-\mathrm{7}\end{array}$ & $\begin{array}{l}\text { high arched palate, } \\
\text { mediastinal } \& \text { intra- } \\
\text { dural neurenteric } \\
\text { cysts, completely } \\
\text { split cord at } c 1-7\end{array}$ & NK \\
\hline 2 & $1, F$ & $\begin{array}{c}C 5-7 \\
L 3-4\end{array}$ & no & $\begin{array}{l}\text { short stature \& } \\
\text { dysmorphic } \\
\text { features }\end{array}$ & $\begin{array}{l}\text { SN, RNM, rt } \\
\text { Sprengel's de- } \\
\text { formity }\end{array}$ & $\mathrm{VF}$ & $\begin{array}{l}\text { ASD \& pulmonary } \\
\text { Stenosis, long fingers, } \\
\text { single kidney, widely } \\
\text { spaced nipples, L3-4 } \\
\text { \& midthoracic fusions } \\
\text { \& kyphosooliosis }\end{array}$ & NK \\
\hline 3 & $1.5, \mathrm{~F}$ & $\begin{array}{l}\mathrm{OC}-\mathrm{Cl} 1 \\
(\mathrm{rt}){ }_{1} \\
\mathrm{C}-3 \\
(\mathrm{pos})\end{array}$ & yes & $\begin{array}{l}\text { episodes of flop- } \\
\text { piness w/ tradyt } \\
\text { cardia \& treath } \\
\text { holding }\end{array}$ & $\begin{array}{l}\text { no dysmorphic } \\
\text { features, alert, } \\
\text { rt arm flacdid } \\
\text { paresis }\end{array}$ & $\begin{array}{l}\text { WF, ant \& pos C-1 } \\
\text { SB, lat defects } \\
\text { in C-2 arch, C-2 } \\
\text { slipped for ward } \\
\text { on C-3, cord } \\
\text { damage }\end{array}$ & NK & $\begin{array}{l}\text { father; } \\
\text { C2-3 } \\
\text { pos fu- } \\
\text { sion }\end{array}$ \\
\hline 4 & 2, M & $\underset{\mathrm{C}-3}{\mathrm{OC}-3}$ & yes & $\begin{array}{l}\text { facial asymmetry, } \\
\text { SN, transient } \\
\text { neck pain }\end{array}$ & SN, RNM & $\begin{array}{l}\text { UF, dens aplasia, } \\
\text { ant } \mathrm{C}-1 \mathrm{SB} \text {, cer- } \\
\text { vical ribs, cervical } \\
\text { hemi vertebrae, } \\
\text { prominent It-1t } \\
\text { ossification }\end{array}$ & $\begin{array}{l}\text { hypospadias, anal } \\
\text { atresia, single rt } \\
\text { kidney, lumbar } \\
\text { scoliosis }\end{array}$ & NK \\
\hline 5 & $2.5, \mathrm{M}$ & $\begin{array}{l}\mathrm{C}-3 \mathrm{i} \\
\mathrm{C4}-5 \\
(\mathrm{pos})\end{array}$ & no & $\begin{array}{l}\text { breath holding } \\
\text { episodes, inci- } \\
\text { dental finding } \\
\text { on chest } x+a y\end{array}$ & $\begin{array}{l}\text { SN, minimal RNM, } \\
\text { rt'Sprengel's } \\
\text { deformity' promi- } \\
\text { nent It mandi ble }\end{array}$ & $\begin{array}{l}\text { WF, ossification in } \\
\text { cervical discs, } \\
\text { prominent It }-1 \mathrm{t} \\
\text { ossification }\end{array}$ & $\begin{array}{l}\text { rt ribs } 2-3 \text { fused, } \\
\text { It T-8 hemi- } \\
\text { wertebra. }\end{array}$ & NK \\
\hline 6 & $5, M$ & $C 2-7$ & no & $\begin{array}{l}\text { aching discom- } \\
\text { fort in legs \& } \\
\text { wrists, it knee } \\
\text { gave inay, in- } \\
\text { creasing cervi- } \\
\text { cothoradc } \\
\text { kyphos }\end{array}$ & $\begin{array}{l}\text { SN, RNM, cervico- } \\
\text { thoracic kyphos }\end{array}$ & $\mathrm{VF}_{\mathrm{SB}} \operatorname{pos} \mathrm{C2}-\mathrm{T1}$ & $\begin{array}{l}\text { cervicothoradic } \\
\text { kyphoscoliosis }\end{array}$ & NK \\
\hline 7 & $6, M$ & $\begin{array}{l}\mathrm{OC}-\mathrm{Cl} \\
\text { T12-L5 }\end{array}$ & $5^{\text {no }}$ & $\begin{array}{l}\text { stiff, k yphotic } \\
\text { neck, small ster- } \\
\text { nomandibular } \\
\text { distance, im- } \\
\text { paired for ward } \\
\text { gaze }\end{array}$ & $\begin{array}{l}\text { marked cervical ky- } \\
\text { phosis, complete } \\
\text { RNM, bowel in- } \\
\text { continenoe }\end{array}$ & $\begin{array}{l}\text { extensi ve VF } \\
\text { (one-bone spine } \\
\text { deformity), ab- } \\
\text { sent cli woaxial } \\
\text { angle, laminar } \\
\text { fusions }\end{array}$ & $\begin{array}{l}\text { short, stu bby fin- } \\
\text { gers \& toes, in- } \\
\text { curving of } 5 \text { th } \\
\text { fingers, bilat } \\
\text { cryptorchism }\end{array}$ & NK \\
\hline 8 & $6, M$ & $\begin{array}{c}\mathrm{OC}-\mathrm{C1} \\
\mathrm{C2}-3 \\
\infty-6\end{array}$ & no & $\begin{array}{l}\text { neck pain, it arm } \\
\& \text { leg meakness }\end{array}$ & $\begin{array}{l}\text { RNM, mild tetra- } \\
\text { paresis, rt hyper- } \\
\text { reflexia, upgoing } \\
\text { It plantar }\end{array}$ & 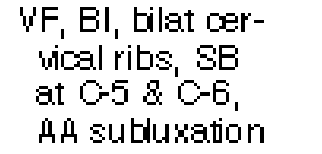 & NK & $\begin{array}{l}\text { uncle; SN } \\
\text { (NI) }\end{array}$ \\
\hline
\end{tabular}

"Abbreviations: AA subluxation = attan toaxal subluxation; ant = anterior; $A \mathrm{SD}=$ atrial se ptal defect; BI = basilar invagination; FM = foramen magnum; $\mathrm{HA}=$ headache; $\mathrm{N}$ = not investigated; $N K=$ not known; $\mathrm{PDA}=$ persistent ductus arteriosus; pos = posterior; $\mathrm{RNM}=$ restriction of neck movements; $\mathrm{SB}=$ spina tifida; $\mathrm{SN}=$ short neck; VF = wertebral fusions; VSD = wentricular septal defect. 


\begin{tabular}{|c|c|c|c|c|c|c|c|c|}
\hline $\begin{array}{l}\text { Case } \\
\text { No. }\end{array}$ & $\begin{array}{c}\text { Age }[y s] \\
\text { Sex }\end{array}$ & $\begin{array}{l}\text { Fusion } \\
\text { Levels }\end{array}$ & $\begin{array}{l}\text { Asym- } \\
\text { metry }\end{array}$ & $\begin{array}{l}\text { Presenting } \\
\text { Symptorns }\end{array}$ & $\begin{array}{c}\text { Clirical } \\
\text { Features } \\
\end{array}$ & $\begin{array}{l}\text { Raddogical } \\
\text { Features }\end{array}$ & $\begin{array}{l}\text { Associated } \\
\text { Anomali es }\end{array}$ & $\begin{array}{l}\text { Family } \\
\text { History }\end{array}$ \\
\hline 9 & $7, \mathrm{~F}$ & $\begin{array}{l}\mathrm{OC}-\mathrm{C1} 1 \\
\text { (pos) } \\
\mathrm{C} 2-\mathrm{T} 1\end{array}$ & yes & $\begin{array}{l}\text { neck pain, tort- } \\
\text { collis, gait } \\
\text { difficulties }\end{array}$ & SN, RNM & $\begin{array}{l}\text { WF, os odontoideum, } \\
\text { An Subluxation, } \\
\text { ant C-1 SB, ab- } \\
\text { sent pos ele- } \\
\text { ments, wide FM, } \\
\text { cervical ribs }\end{array}$ & $\begin{array}{l}\text { partially split cond } \\
\text { at medulla-c-2, } \\
\text { occi pital meningo- } \\
\text { cele, hypoplastic } \\
\text { It lung, tracheal } \\
\text { Stenosis, } 1 \text { kidney } \\
\text { VSD/ASD, PDA }\end{array}$ & NK \\
\hline 10 & $7.5, \mathrm{M}$ & $\begin{array}{l}C 2-3 \\
C 4-6 \\
T 1-5\end{array}$ & yes & $\begin{array}{l}\text { restriction of It } \\
\text { hand extension } \\
\& \text { It shoulder } \\
\text { abduction }\end{array}$ & $\begin{array}{l}\text { SN, minimal RNM, } \\
\text { It Sprengel's de- } \\
\text { formity }\end{array}$ & $\begin{array}{l}\text { WF, } \mathrm{C7}-\mathrm{T} 1 \text { hemi- } \\
\text { wertebrae }\end{array}$ & It ribs $1-2$ fused & NK \\
\hline 11 & $11, F$ & $\begin{array}{l}\mathrm{OC}-\mathrm{C} 1 \\
\text { (ant } \mid \mathrm{t}-\mathrm{t} \text { t) } \\
\mathrm{C}-3-3 \\
\mathrm{C}-\mathrm{T}_{1}\end{array}$ & no & $\begin{array}{l}\text { one episode of } \\
\text { collapse while } \\
\text { horse back riding }\end{array}$ & RNM & $\begin{array}{l}\text { VF, BI, AA sublux- } \\
\text { ation, cer wical rib }\end{array}$ & $\begin{array}{l}\text { upper thoradic } \\
\text { sooliosis }\end{array}$ & NK \\
\hline 12 & $11, M$ & $\begin{array}{l}\mathrm{OC}-\mathrm{C1} \\
(\mathrm{pos} \mid \mathrm{t}-\mathrm{t} t), \\
\mathrm{C2-4} \\
\mathrm{C5}-\mathrm{T} 2\end{array}$ & yes & $\begin{array}{l}\text { neck pain, } 00 \times a- \\
\text { sional stum tling }\end{array}$ & $\begin{array}{l}\text { SN, low hairline, } \\
\text { RNM, h yperre- } \\
\text { flexa, minimal } \\
\text { rt leg paresis }\end{array}$ & $\begin{array}{l}\text { WF, short cliws, } \\
\text { prominent It }-1 t \\
\text { ossification }\end{array}$ & $\begin{array}{l}\text { It T-3 hemi vertetra, } \\
\text { anal atresia, deft } \\
\text { palate, renal ec- } \\
\text { topia. }\end{array}$ & NK \\
\hline 13 & $11, F$ & $\mathrm{C} 2-\mathrm{T} 2$ & yes & $\begin{array}{l}\text { increasing It torti- } \\
\text { collis }\end{array}$ & $\begin{array}{l}\text { facial asymmetry, } \\
\text { RNM }\end{array}$ & $\begin{array}{l}\text { hemi wertetral fu- } \\
\text { sions, cervical } \\
\text { scoliosis, pro- } \\
\text { gressive bone } \\
\text { fusion }\end{array}$ & $\begin{array}{l}\text { occipital meningo- } \\
\text { cele, scalp epi- } \\
\text { dermal cyst, hy- } \\
\text { droce phalus, par- } \\
\text { tallysplit cervical } \\
\text { cord }\end{array}$ & NK \\
\hline 14 & $11, M$ & $\begin{array}{l}O C-C 1 \\
\text { (ant) } \\
C 2-4 \\
C 5-7 \\
T 1-3\end{array}$ & yes & $\begin{array}{l}\text { rt torticollis, high } \\
\text { It shoulder, } \\
\text { short It leg }\end{array}$ & $\begin{array}{l}\text { rt torticollis, It } \\
\text { Sprengel's de- } \\
\text { formity cervico- } \\
\text { thoracic scolio- } \\
\text { sis (C5-T4) }\end{array}$ & VF & $\begin{array}{l}\text { Chiari I, hypoplastic } \\
\text { rt side of T-2 } \\
\text { wertebra. }\end{array}$ & NK \\
\hline 15 & $11, M$ & $\begin{array}{l}C 2-5 \\
06-7 \\
T 1-3\end{array}$ & yes & $\begin{array}{l}\text { tracheomalacia, } \\
\text { fistula at age } 1 \\
\text { yr, kyphosoolio- } \\
\text { sis, neurogenic } \\
\text { bladder }\end{array}$ & $\begin{array}{l}\text { SN, RNM, high } \\
\text { thoracic scoliosis } \\
\text { rib hump \& prom- } \\
\text { inent scapula, } \\
\text { small stature, rig- } \\
\text { id thoracic scine }\end{array}$ & $\begin{array}{l}\text { WF, pos C-1 \& } \\
\text { C-7 SB, rt C-7 } \\
\text { \& T-2 hemi ier- } \\
\text { tetrae, progres- } \\
\text { sive bone fusion }\end{array}$ & NK & NK \\
\hline 16 & $12, M$ & $\begin{array}{l}C 2-3 \\
C 4-5 \\
C 6-7\end{array}$ & no & $\begin{array}{l}\text { transient tetra- } \\
\text { plegia after mi- } \\
\text { nor head injury, } \\
\text { delayed mile- } \\
\text { stones in motor } \\
\text { development }\end{array}$ & $\begin{array}{l}\text { SN, RNM, facial } \\
\text { asymmetry, mixed } \\
\text { hearing loss, } \\
\text { masted intrinsic } \\
\text { musdes, mild } \\
\text { tetraparesis, hyper- } \\
\text { reflexia, upgoing } \\
\text { plantars }\end{array}$ & $\begin{array}{l}\text { WF, os odontoideum, } \\
\text { An subluxation, } \\
\text { cord com pression }\end{array}$ & $\begin{array}{l}\text { claw hands, rt } \\
\text { flexon deformity } \\
\text { of } 4 \text { th } \& 5 \text { th fingers }\end{array}$ & NK \\
\hline
\end{tabular}

"Abbre viations: AA subluxation = attan toaxal subluxation; ant = anterior; ASD = atrial se ptal defect; BI = basilar invagination; FMI = foramen magnum; $\mathrm{HA}=$ headache; $N \mathbb{N}=$ not investigated; $N K=$ not known; PDA = persistent ductus arteriosus; pos = posterior; $\mathrm{RNM}=$ restriction of neck movements; $\mathrm{SB}=$ spina bifida; $\mathrm{SN}=$ short neck; VF = vertebral fusions; VSD = wentricular septal defect. 
TABLE 1, CONT NUED

CINICAL SUMMARV OF 30 PATIENTS WITH KFS

\begin{tabular}{|c|c|c|c|c|c|c|c|c|}
\hline $\begin{array}{l}\text { Case } \\
\text { No. }\end{array}$ & $\begin{array}{c}\text { Age }[y s], \\
\text { Sex }\end{array}$ & $\begin{array}{l}\text { Fusion } \\
\text { Levels }\end{array}$ & $\begin{array}{l}\text { Asym- } \\
\text { metry }\end{array}$ & $\begin{array}{l}\text { Presenting } \\
\text { Symptorns }\end{array}$ & $\begin{array}{c}\text { Clirical } \\
\text { Features } \\
\end{array}$ & $\begin{array}{l}\text { Raddogical } \\
\text { Features }\end{array}$ & $\begin{array}{l}\text { Associated } \\
\text { Anomali es }\end{array}$ & $\begin{array}{l}\text { Family } \\
\text { History }\end{array}$ \\
\hline 17 & 16 , M & $\underset{\mathrm{C}-3}{\mathrm{OC}-\mathrm{C}}$ & no & $\begin{array}{l}\text { progressive gait } \\
\text { \& swallowing } \\
\text { dificul ties, stiff } \\
\text { \& numb legs, } \\
\text { ocd pital HA }\end{array}$ & $\begin{array}{l}\text { SN, RNM, facial } \\
\text { asymmetry, tetra- } \\
\text { spasticity hyper- } \\
\text { reflexia, upgoing } \\
\text { plantars, nystag- } \\
\text { mus }\end{array}$ & $\begin{array}{l}\text { VF, BI, hypoplastic } \\
\text { dens, ÁA sublux- } \\
\text { ation, prominent } \\
\text { lt-t ossification }\end{array}$ & Ohiari I & $\begin{array}{l}\text { trother; } \\
\text { C2-3 \& } \\
04-5 \text { fu- } \\
\text { sions }\end{array}$ \\
\hline 18 & $19, \mathrm{M}$ & $\begin{array}{r}\mathrm{OC}-\mathrm{C} 2 \\
(\mathrm{pos})\end{array}$ & yes & $\begin{array}{l}\text { occipital HA, } \\
\text { nausea, easy } \\
\text { choking when } \\
\text { drinking, heavy } \\
\text { legs, unsteady' } \\
\text { gait }\end{array}$ & $\begin{array}{l}\text { mild dysarthria, } \\
\text { nystagm us, gag } \\
\text { hyporeflexia. }\end{array}$ & $\mathrm{VF}, \mathrm{BI}$ & Chiari I & NK \\
\hline 19 & $20, F$ & $\mathrm{C} 2-\mathrm{T5}$ & no & $\begin{array}{l}\text { marked deformity } \\
\text { of neck, sutman- } \\
\text { dibular hirsutism, } \\
\text { facial hypoplasia }\end{array}$ & $\begin{array}{l}\text { RNM, Sprengel's } \\
\text { deformity, SN, } \\
\text { rt conductive } \\
\text { hearing loss, hy- } \\
\text { perreflexia, stra- } \\
\text { tism, mirror } \\
\text { mowements }\end{array}$ & $\begin{array}{l}\text { WF, hypoplastic } \\
\text { wertebrae, upper } \\
\text { cervical SB, 'ery } \\
\text { wide FM, small } \\
\text { pos fossa. }\end{array}$ & $\begin{array}{l}\text { partially split cond } \\
\text { from FM to c-2, } \\
\text { pol ycystic ovaries, } \\
\text { Chiari III, high } \\
\text { arched palate, } \\
\text { bifid uwula. }\end{array}$ & NK \\
\hline 20 & 21, M & $9-6$ & no & $\begin{array}{l}\text { transient tetraple- } \\
\text { gia after h yper- } \\
\text { flexion injury of } \\
\text { neck }\end{array}$ & $\begin{array}{l}\text { minimal RNM, re- } \\
\text { sidual It arm } \\
\text { meakness, hyper- } \\
\text { reflexia, musde } \\
\text { masting, spinal } \\
\text { ataxia. }\end{array}$ & $\begin{array}{l}\text { WF, } C 3-4 \text { degen- } \\
\text { erative changes }\end{array}$ & $\begin{array}{l}\text { posttraumatic } \\
\text { syrinx }\end{array}$ & NK \\
\hline 21 & $23, F$ & $\underset{\mathrm{C}-3}{\mathrm{OC}-\mathrm{C} 1}$ & yes & $\begin{array}{l}\text { rt torticollis, oc- } \\
\text { cipital HA, neck } \\
\& \text { bilat shoulder } \\
\text { pain }\end{array}$ & $\begin{array}{l}\text { SN, RNM, facial } \\
\text { asymmetry, bilat } \\
\text { absent sterno- } \\
\text { mastoid musdes }\end{array}$ & VF, short climus & $\begin{array}{l}\text { Chiari I, large rt } \\
\text { wertebral artery } \\
\text { im pressing pons }\end{array}$ & $\begin{array}{l}\text { sister had } \\
\text { encepha- } \\
\text { looele, tor- } \\
\text { toollis, } 1 \\
\text { kidney } \\
\text { (NI) }\end{array}$ \\
\hline 22 & 25, M & $\underset{\mathrm{C}-3}{\mathrm{OC}-3}$ & yes & $\begin{array}{l}\text { neck \& occi pital } \\
\text { pain, num tness } \\
\text { in fingertips, leg } \\
\text { stiffness }\end{array}$ & $\begin{array}{l}\text { SN, RNM, hyperre- } \\
\text { flexa, tilat Hoff- } \\
\text { mann's reflex }\end{array}$ & $\begin{array}{l}\text { WF, short clims, } \\
\mathrm{BI}\end{array}$ & Chiari I, syrinx & NK \\
\hline 23 & $30, F$ & $\underset{\mathrm{C}-3}{\mathrm{OC}-3}$ & yes & $\begin{array}{l}\text { dizyspells, ny- } \\
\text { stagmus, dys- } \\
\text { phagia, nasal } \\
\text { speedh, It arm } \\
\text { paresthesia, } \\
\text { occipital HÁ }\end{array}$ & $\begin{array}{l}\text { minimal RNM, nyt } \\
\text { stagmus, slighty } \\
\text { hoarse woice, rt- } \\
\text { sided tongue atro- } \\
\text { phy, im paired } \\
\text { taste on rt, ataxia }\end{array}$ & $\mathrm{VF}, \mathrm{BI}$ & Chiari I, syrinx & NK \\
\hline
\end{tabular}

"Abbre viations: AA subluxation = attan toaxal subluxation; ant = anterior; ASD = atrial se ptal defect; BI = basilar invagination; FM = foramen magnum; $\mathrm{HA}=$ headache; $N \mathbb{N}=$ not investigated; $N K=$ not known; $P D A ́$ = persistent ductus arteriosus; pos = posterior; $\mathrm{RNM}=$ restriction of neck movements; $\mathrm{SB}=$ spina tifida; $\mathrm{SN}=$ short neck; VF = wertebral fusions; VSD = wentricular septal defect. 
TABLE 1, CONT NUED

CINICAL SUMMARV OF 30 PATIENTS WITH KFS

\begin{tabular}{|c|c|c|c|c|c|c|c|c|}
\hline $\begin{array}{l}\text { Case } \\
\text { No. }\end{array}$ & $\begin{array}{c}\text { Age }(y s) \\
\text { Sex }\end{array}$ & $\begin{array}{l}\text { Fusion } \\
\text { Levels }\end{array}$ & $\begin{array}{l}\text { Asym- } \\
\text { metry }\end{array}$ & $\begin{array}{l}\text { Presenting } \\
\text { Symptorns }\end{array}$ & $\begin{array}{c}\text { Clirical } \\
\text { Features }\end{array}$ & $\begin{array}{l}\text { Radological } \\
\text { Features }\end{array}$ & $\begin{array}{l}\text { Associated } \\
\text { Anomali es }\end{array}$ & $\begin{array}{l}\text { Family } \\
\text { History }\end{array}$ \\
\hline 24 & $32, \mathrm{M}$ & $\begin{array}{c}\mathrm{OC}-\mathrm{C} 1 \\
\mathrm{C2}-3 \\
\mathrm{C4}-5\end{array}$ & yes & $\begin{array}{l}\text { numbness in arms } \\
\& \text { legs, weakness } \\
\text { in arms, unsteady } \\
\text { gait }\end{array}$ & $\begin{array}{l}\text { RNM, } 4+5 \text { spastic } \\
\text { tetraparesis, hy- } \\
\text { perreflexia, it up- } \\
\text { going plantar, ny- } \\
\text { stagmus, rt } 12 \text { th } \\
\text { cranial ner'e } \\
\text { palsy }\end{array}$ & $\begin{array}{l}\text { WF, dysplasia of } \\
\text { C-1 lat masses, } \\
\text { AA subluxation, } \\
\text { short deformed } \\
\text { dens, ant med- } \\
\text { ullary compres- } \\
\text { sion }\end{array}$ & Chiari I & NK \\
\hline 25 & $38, F$ & $\frac{\mathrm{OC}-\mathrm{C4}}{\mathrm{C}-\mathrm{T2}}$ & yes & $\begin{array}{l}\text { neck pain, clumsy } \\
\text { rt arm, crunching } \\
\text { sensation in nedk } \\
\text { when tuming } \\
\text { head }\end{array}$ & $\begin{array}{l}\text { SN, RNM, hairy } \\
\text { patch at low back, } \\
\text { It divergent squint, } \\
\text { minimal meakness } \\
\text { of shoulder \& hip } \\
\text { musdes }\end{array}$ & $\begin{array}{l}\text { VF, C4-5 degen- } \\
\text { erative changes, } \\
\text { dens fused to cli- } \\
\text { ws, absent diwo- } \\
\text { axial angle, lami- } \\
\text { nar fusions, prom- } \\
\text { inent It-1t ossifica- } \\
\text { ton, c-5 butterf y } \\
\text { wertebra, c-4, C-7, } \\
\text { T-1 hem iverte trae }\end{array}$ & $\begin{array}{l}\text { tilat ribs } 1-3 \\
\text { fused, om o- } \\
\text { wertebral bone }\end{array}$ & $\begin{array}{l}\text { great-grand- } \\
\text { mother \& } 2 \\
\text { cousins } \\
\text { had KFS }\end{array}$ \\
\hline 26 & $40, M$ & $\begin{array}{c}C 6-7 \\
\text { T1-2 }\end{array}$ & no & $\begin{array}{l}\text { complete tetraple- } \\
\text { gia after traffic } \\
\text { accident }\end{array}$ & $\begin{array}{l}\text { no significant } \\
\text { clinical fe atures }\end{array}$ & $\begin{array}{l}\text { WF, } C 5-6 \text { fracture } \\
\text { dislocation } \& \text { cord } \\
\text { compression }\end{array}$ & $\begin{array}{l}\text { rib necks } 1-3 \\
\text { enlarged }\end{array}$ & NK \\
\hline 27 & $46, F$ & $\begin{array}{l}\mathrm{OC}-\mathrm{Cl} 1 \\
(\mathrm{ant} \mid \mathrm{t}-\mathrm{t})_{1} \\
\mathrm{C} 2-3\end{array}$ & no & $\begin{array}{l}\text { neck pain, cough- } \\
\text { HA, nausea, } \\
\text { giddiness, swal- } \\
\text { lo wing problems }\end{array}$ & $\begin{array}{l}\text { SN, RNM, de- } \\
\text { creased left gag } \\
\& \text { palatal moie- } \\
\text { ments }\end{array}$ & $\begin{array}{l}\text { VF, pos C-1 SB, } \\
\text { short dims, Bl }\end{array}$ & Chiari I & $\begin{array}{l}\text { aunt had } \\
\text { SN (NI) }\end{array}$ \\
\hline 28 & $48, F$ & $\begin{array}{c}O C-C 1 \\
(p 0 s), \\
C 2-7\end{array}$ & no & $\begin{array}{l}\text { neck pain, weak \& } \\
\text { numb rt arm, uri- } \\
\text { nary frequency } \\
\text { It occipital HA, } \\
\text { occasional } \\
\text { stum bling }\end{array}$ & $\begin{array}{l}\text { SN, RNM, stiff lum- } \\
\text { bar spine, tilat } 6 \text { th } \\
\text { cranial ner 'e palsy } \\
\& \text { mild hearing loss, } \\
\text { mild rt hemiparesis, } \\
\text { rt } C 6-T 1 \text { hypes- } \\
\text { thesia. }\end{array}$ & $\begin{array}{l}\text { WF, ant } \mathrm{C}-1 \mathrm{SB} \text {, } \\
\text { short diws, oer- } \\
\text { wical ribs, } \mathrm{O} 2 \text { ar- } \\
\text { ticulates w/cliws, } \\
\text { prominent It } \rightarrow \mathrm{t} \\
\text { ossification }\end{array}$ & $\begin{array}{l}\text { completely split } \\
\text { cord at medulla } \\
c-3\end{array}$ & NK \\
\hline 29 & $50, F$ & $\begin{array}{l}\mathrm{OC}-\mathrm{Cl} 1 \\
(\mathrm{ant} \mid \mathrm{t}-\mathrm{t}), \\
\mathrm{C}-3 \\
\mathrm{C}-6\end{array}$ & yes & $\begin{array}{l}\text { It scapular pain, } \\
\text { numbness in lt } \\
\text { axilla \& upper } \\
\text { arm }\end{array}$ & $\begin{array}{l}\text { It Sprengel's de- } \\
\text { formity restric- } \\
\text { ton of It shoulder } \\
\text { movements, hyp- } \\
\text { esthesia in It } \\
\text { axilla. }\end{array}$ & $\begin{array}{l}\text { VF, degenerative } \\
\text { changes at } C 3-4\end{array}$ & NK & NK \\
\hline 30 & $66, F$ & $\underset{\mathrm{C}-3}{\mathrm{OC}-\mathrm{C} 1}$ & yes & $\begin{array}{l}\text { neck pain, dizzy } \\
\text { spells }\end{array}$ & $\begin{array}{l}\text { SN, RNM, deteri- } \\
\text { orating It hearing, } \\
\text { rt deatness, pos- } \\
\text { itive Rom berg's } \\
\text { sign }\end{array}$ & $\begin{array}{l}\text { WF, hypoplastic } \\
\text { dens, an terior } \\
\text { C-1 SB, rheu- } \\
\text { matoid changes, } \\
\text { Bl }\end{array}$ & $\begin{array}{l}\text { high arched pal- } \\
\text { ate, heumatoid } \\
\text { arthritis }\end{array}$ & NK \\
\hline
\end{tabular}

"Abbre viations: AA subluxation = atlan toaxial subluxation; ant = anterior; $A$ SD = atrial se ptal defect; $B \mathrm{Bl}=$ basilar invagination; $\mathrm{FM}=$ foramen magnum; $\mathrm{HA}=$ headache; $N \mathrm{~N}=$ not investigated; $N K=$ not known; $\mathrm{PDA}=$ persistent ductus arteriosus; pos = posterior; $\mathrm{RNM}=$ restriction of neck movements; $\mathrm{SB}=$ spina bifida; $\mathrm{SN}$ = short neck; $\mathrm{VF}=$ wertebral fusions; $\mathrm{VSD}=$ ventricular septal defect.

\section{RESULTS}

\section{Clinical and Radiological Findings}

Neck pain (10 patients), gait difficulties (six patients), weakness or numbness of limbs (six patients each), occipital headache (five patients), torticollis (four patients), dizziness (four patients), and swallowing problems (three patients) were the most frequent chronic symptoms. In three patients the presence of vertebral fusion was an incidental finding when radiographs were obtained following acute cervical trauma. The most common clinical features were restriction of neck movements ( 25 cases), short neck (18 cases), Sprengel's deformity (seven cases), and facial asymmetry (five cases), whereas paresis (nine cases), hyperreflexia (eight cases), deafness (four cases), and other cranial nerve palsies (five cases) were the most common neurological signs.

In all patients one or more levels of fusion in the cervical spine had occurred. The most frequently involved 
vertebral levels at which fusion had occurred were C-1 assimilation to occiput and between C2-3 (Fig. 1). Other radiological features included anterior or posterior spina bifida in 10 patients, basilar invagination in eight, atlantoaxial subluxation in six, cervical ribs in five, hemivertebra in three, hypoplastic odontoid process in three, os odontoideum in two, and dens aplasia in one patient.

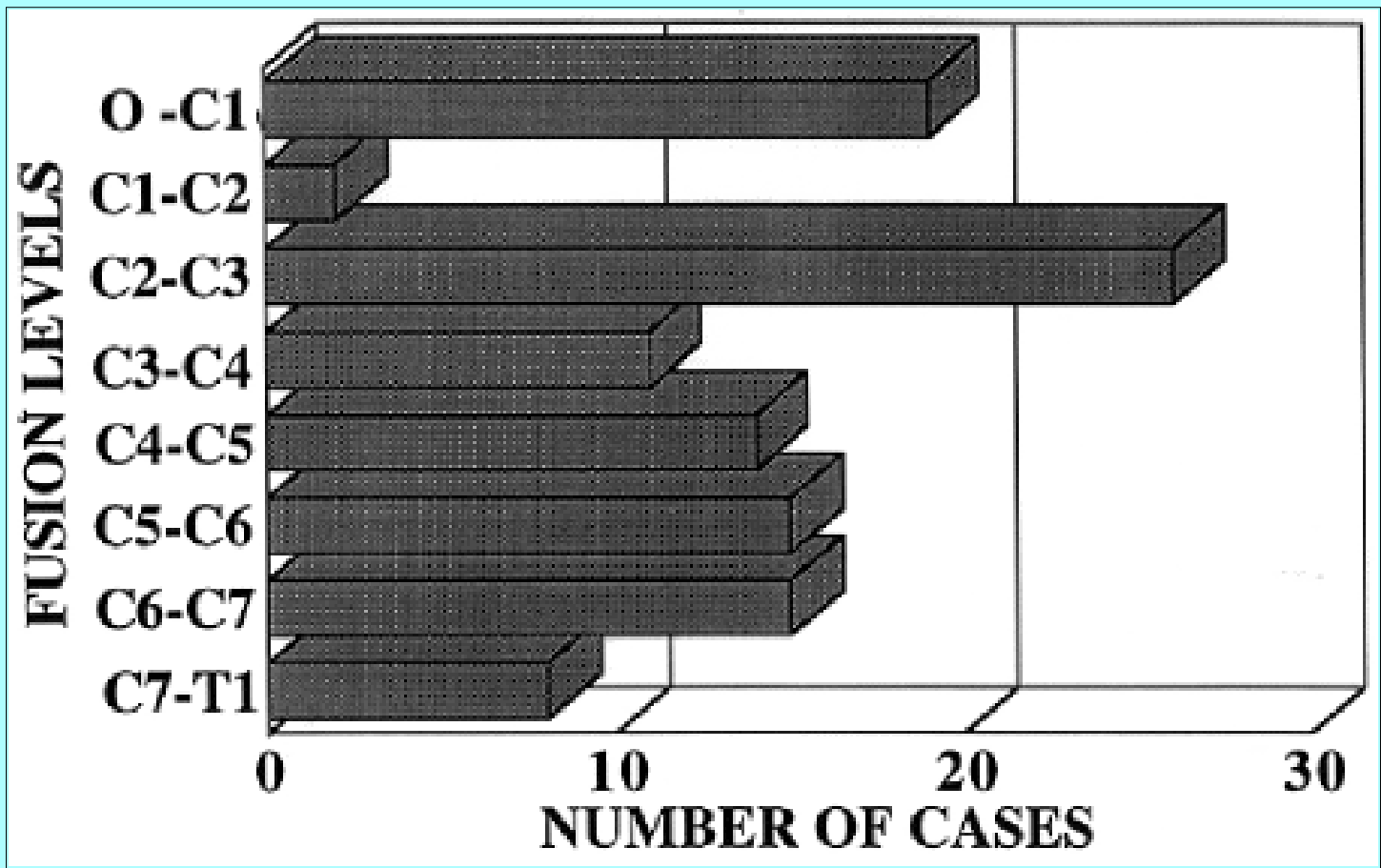

Fig. 1. Bar graph showing the number of cervical fusions by involved level. Total number exceeds 30 because in 29 patients there was more than one fused level between occiput and T-1. $\mathrm{O}=$ occiput.

The most common associated anomalies were Chiari I malformation (eight cases), partially or completely split cervical cord (five cases), high arched or cleft palate (four cases), enlarged or fused ribs (four cases), scoliosis (four cases), single or ectopic kidney (four cases), syrinx (three cases), anal atresia (two cases), occipital meningocele (two cases), and cardiac septal defect (two cases).

In three cases there was a positive family history for cervical spine fusions: two cousins and a great-grandmother of one patient, the father of another, and the brother of a third patient had proven cervical vertebral fusions. In three other cases, the family history was suggestive of KFS, but these cases were not confirmed radiographically.

\section{Observed Radiological Patterns of Malformation}

In 11 patients (37\%) only subaxial fusions were demonstrated, and in three the diagnosis was made incidentally after the patients sustained a severe spinal cord injury.

In 19 patients (63\%) either partial (nine patients) or complete (10 patients) assimilation of atlas to occiput was demonstrated. In eight of the 19 patients an associated C2-3 fusion was revealed, and in 10 more extensive subaxial fusions were found that sometimes extended into the thoracic spine (Fig. 2). In one patient vertebral fusions had formed between occiput-C2. 


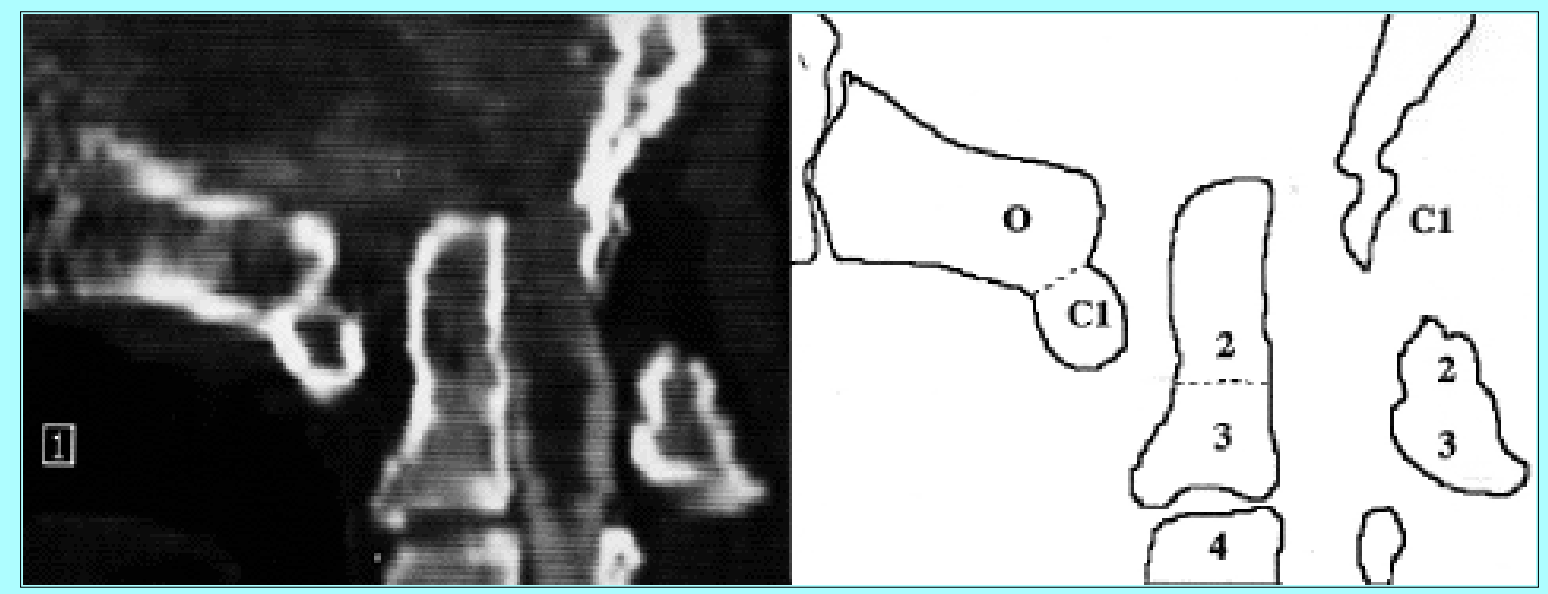

Fig. 2. Left: Midsagittal reformatted CT myelogram obtained in a patient in whom atlas assimilation into occiput, basilar invagination, C2-3 anterior and posterior fusion and atlantoaxial subluxation causing anterior medullary compression were revealed. Right: Line diagram showing the fusion pattern. $\mathrm{O}=$ occiput.

In two patients midline fusion through the craniovertebral junction was observed, and in both the clivoaxial angle was absent (Fig. 3). Only one mobile segment from the clivus to T-2 was demonstrated in one of these patients, whereas in the other almost complete fusion of the spine was revealed, with a fusion bar connecting the dorsal part of the vertebral bodies ("one-bone spine").

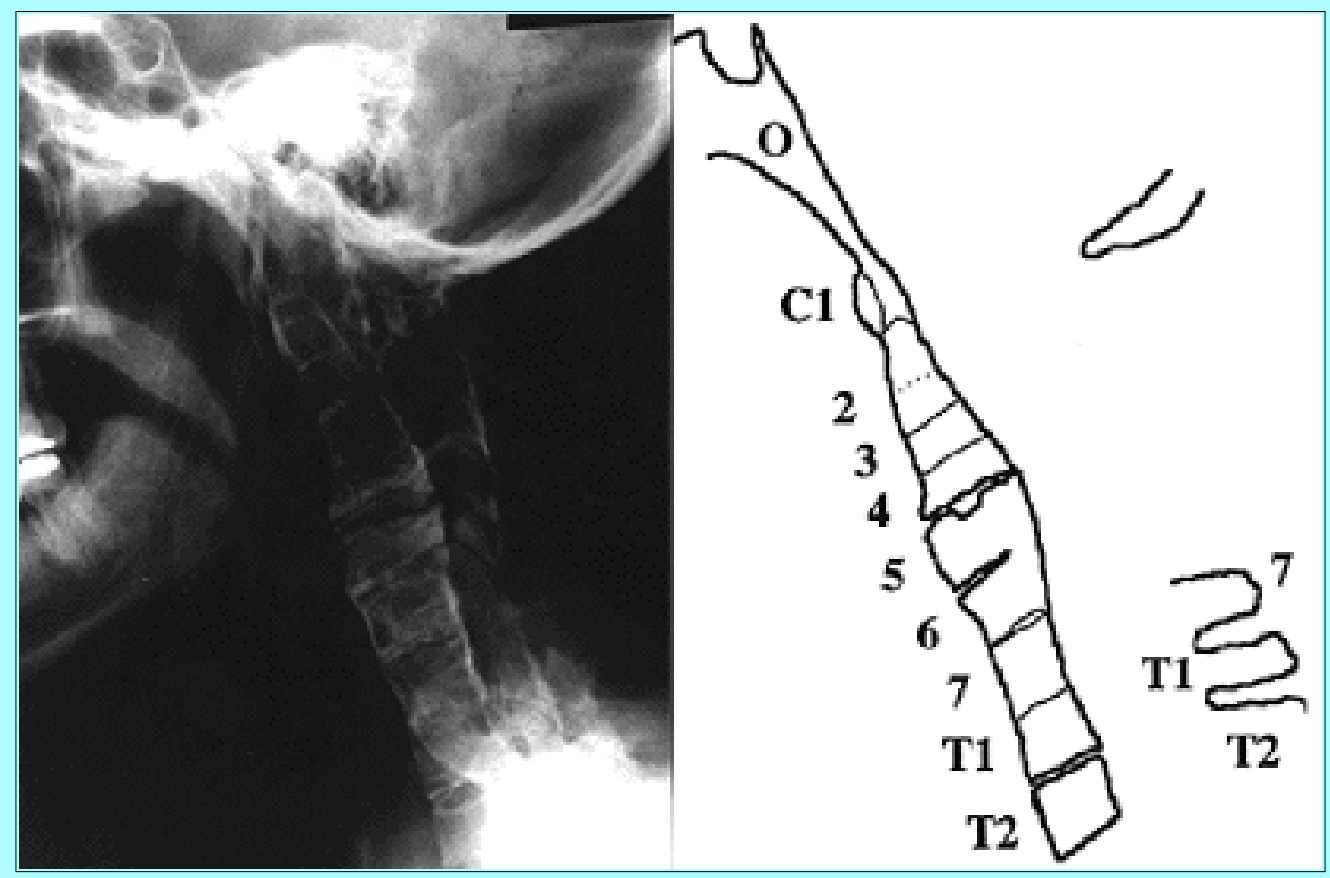

Fig. 3. Left: Lateral cervical radiograph showing extensive fusions of the anterior and posterior elements between clivus and T-2. Right: Traced-line diagram illustrating an axial fusion through the craniovertebral junction and the single motion segment between $\mathrm{C} 4-5$. $\mathrm{O}=$ occiput.

In 17 cases $(57 \%)$ there was marked left-right asymmetry of fusion, which was more prominent when vertebral bodies showed left and right halves of ossification (four cases) or when hemivertebrae were found (five cases). Hemivertebrae, when present, seemed to demonstrate independent fusion patterns on the left and right sides (Fig. 4). In 13 of the patients in whom asymmetrical vertebral fusion was found, C-1 assimilation to occiput was present, but asymmetry was found only in seven cases in the region of $\mathrm{C}-1$ assimilation. 


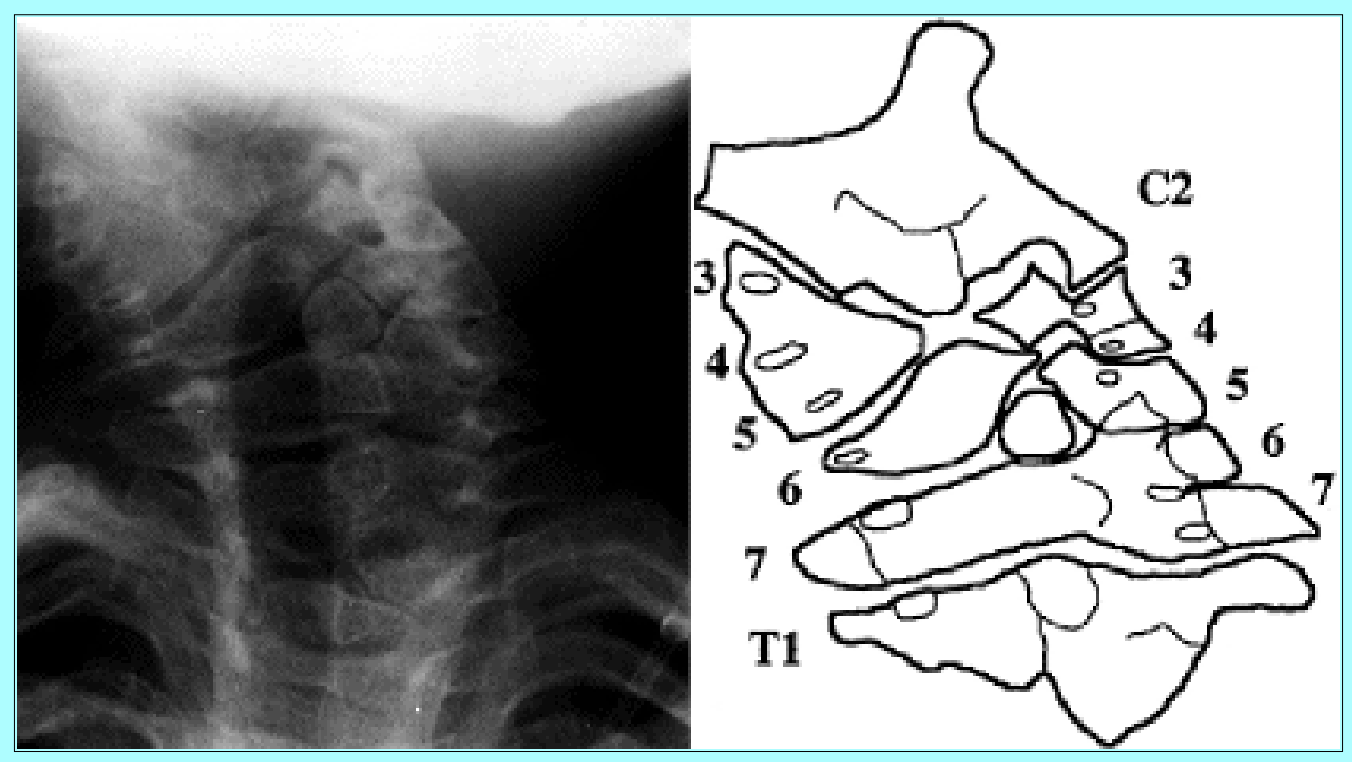

Fig. 4. Left: Anteroposterior cervical radiograph revealing marked left-right asymmetrical fusion pattern of hemivertebrae. Right: Line diagram in which the numbers of individual segments are indicated on the left and right sides.

In seven cases (23\%), axial CT or MR imaging revealed that the fused vertebral bodies had a small anteroposterior diameter: they were narrow and wide with distinct left and right halves and a midsagittal sclerotic zone. In some cases a small round area was visible in the middle of the vertebral body (Fig. 5).

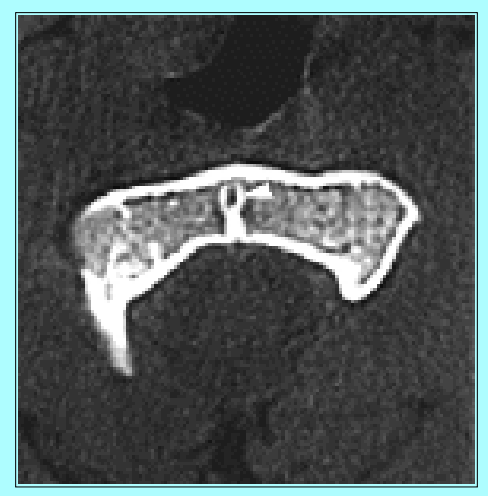

Fig. 5. Axial CT scan (obtained through a bone window) revealing a fused vertebral body with small anteroposterior diameter and a midsagittal sclerotic zone separating the left and right halves. Note the round sclerotic area in the midline, which may mark the position of the notochord (arrowhead).

In two patients in whom radiographs were obtained before 1 year of age and also years later, an increase in the number of fused levels was demonstrated; thus, progressive bone fusion seemed to occur during the aging process (Fig. 6). 


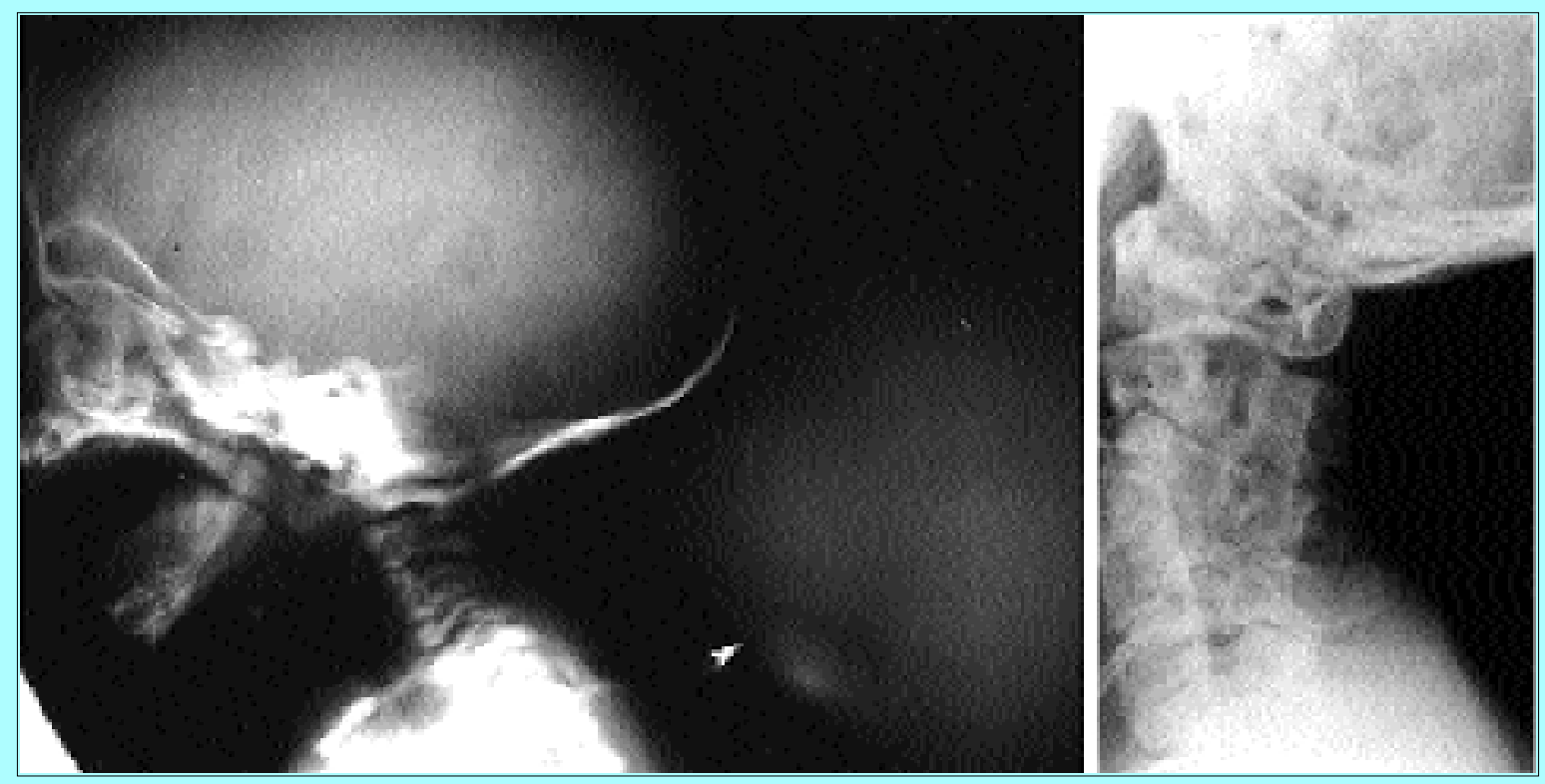

Fig. 6. Left: Radiograph, lateral view, obtained 2 weeks after birth demonstrating well-segmented posterior cervical elements and fusion between C3-5. Note the shadow of a large occipital meningocele (arrowhead). Right: Lateral cervical radiograph obtained in the same patient at 8 years of age demonstrating that the bone fusion increased and now affects anterior and posterior elements of C3-7.

\section{DISCUSSION}

There have been several attempts to identify clinical patterns of KFS to determine those patients at high risk,[37,38,42] whereas other investigators have analyzed radiological findings and fusion pattern.[39,57] Assimilation of the atlas with C2-3 fusion and also more extensive fusions of the cervical vertebrae have already been identified as radiological patterns of the malformation.[38,59] Although there is some data on the causes of the abnormality, $[6,20,49]$ in our report we endeavor to integrate, for the first time, the putative role of recently described genetic factors, known to be associated with vertebral anomalies in transgenic and mutant mice, with the development of the clinical dysmorphology just described (Table 2). To contextualize this exercise we provide a brief review of the normal embryonic development of the spine and summarize our present knowledge of its genetic control (for a full account of vertebral column development, see Dietrich and Kessel[14]).

\begin{tabular}{|c|c|}
\hline \multicolumn{2}{|c|}{$\begin{array}{l}\text { TABLE } 2 \\
\text { GCAL PATERNS AND SUGGESTED } \\
\text { MENTAL MECHAN SMS }\end{array}$} \\
\hline Otserved Paltem & Suggested Developmental Mecharism \\
\hline $\begin{array}{l}\text { homeotic transformation } \\
\text { wertebral fusions } \\
\text { It-rt asymmetrical fusion } \\
\text { It-rt ossification \& progressive } \\
\text { bone fusion }\end{array}$ & $\begin{array}{l}\text { Haxgenes } \\
\text { Paxgenes } \\
\text { paraxial mesoderm deficiency lack } \\
\text { of communicaton across midline } \\
\text { wertebral fusion occurs before or } \\
\text { during chondrification }\end{array}$ \\
\hline
\end{tabular}

\section{Development of the Spine}

The mammalian body axis is established during gastrulation when cells migrate through the primitive streak and the three layers of the embryonic disc are generated. In the midline some of the cells pass through the anterior tip of the streak (called the primitive node) and give rise to a rodlike structure, the notochord. This causes the overlying ectoderm to become the neural plate, which later will form the neural tube. The paraxial mesoderm, lying on either side of the notochord, segments progressively in a craniocaudal direction to form the paired blocks of tissue known as somites, which subsequently transform into epithelial spheres. The first five (occipital) somites appear in stage 9 (at approximately 20 days), followed by the seven cervical somites over the next 2 to 4 days.[40] Later, while the 
dorsolateral parts of the somites retain their epithelial arrangement to form dermamyotomes, the ventromedial parts lose their epithelial structure, and in these areas (the so-called sclerotomes) the cells will migrate toward the midline to surround the notochord and form the perichordal cellular zone. A distinction between lateral and axial differentiation needs to be recognized,[37,59] because the lateral parts of sclerotomes separate into low-cell density cranial and high-cell density caudal halves from stage 13 onward (at approximately 28 days). The loose halves contain the spinal nerves, dorsal root ganglia, and the intersegmental vessels, whereas the dense caudal halves give rise to the lateral processes and neural arches of vertebrae. During the process of resegmentation, the loose half of a sclerotome and the dense half of the sclerotome cranial to it will form a vertebra. Axially, the perichordal region also subsequently shows zones of high- and low-cell density (from stage 14 onward; at approximately 32 days). The high-cell density zone contributes to the formation of intervertebral discs, whereas the low-density areas develop into the centra of vertebrae. $[18,27,40,58]$

It has been shown experimentally that the somites, and even the unsegmented paraxial mesoderm, are already skeletogenically predetermined with respect to the morphological features characteristic of their axial level. For example, thoracic somites that are heterotopically grafted to the cervical region give rise to ribs in the host embryos.[28] Consequently, the developmental fate of sclerotome cells must be specified long before the identity of the individual vertebral segment is morphologically apparent. This morphogenetic specification of vertebral phenotype, along the embryonic axis, is an early event controlled by the Hox genes.[26]

\section{Homeotic Transformation (C-1 Assimilation) and Hox Genes}

The Hox genes are a family of regulatory genes (with a phylogenetically highly conserved domain called the "homeobox"), which appears to play a fundamental role in the establishment of the body plan, including specification of the axial skeleton. All vertebrates, including human beings, contain 38 Hox genes that are distributed on four linkage groups (or clusters) designated Hox A, B, C, and D on chromosomes 6, 11, 15, and 2, respectively (Fig. 7).

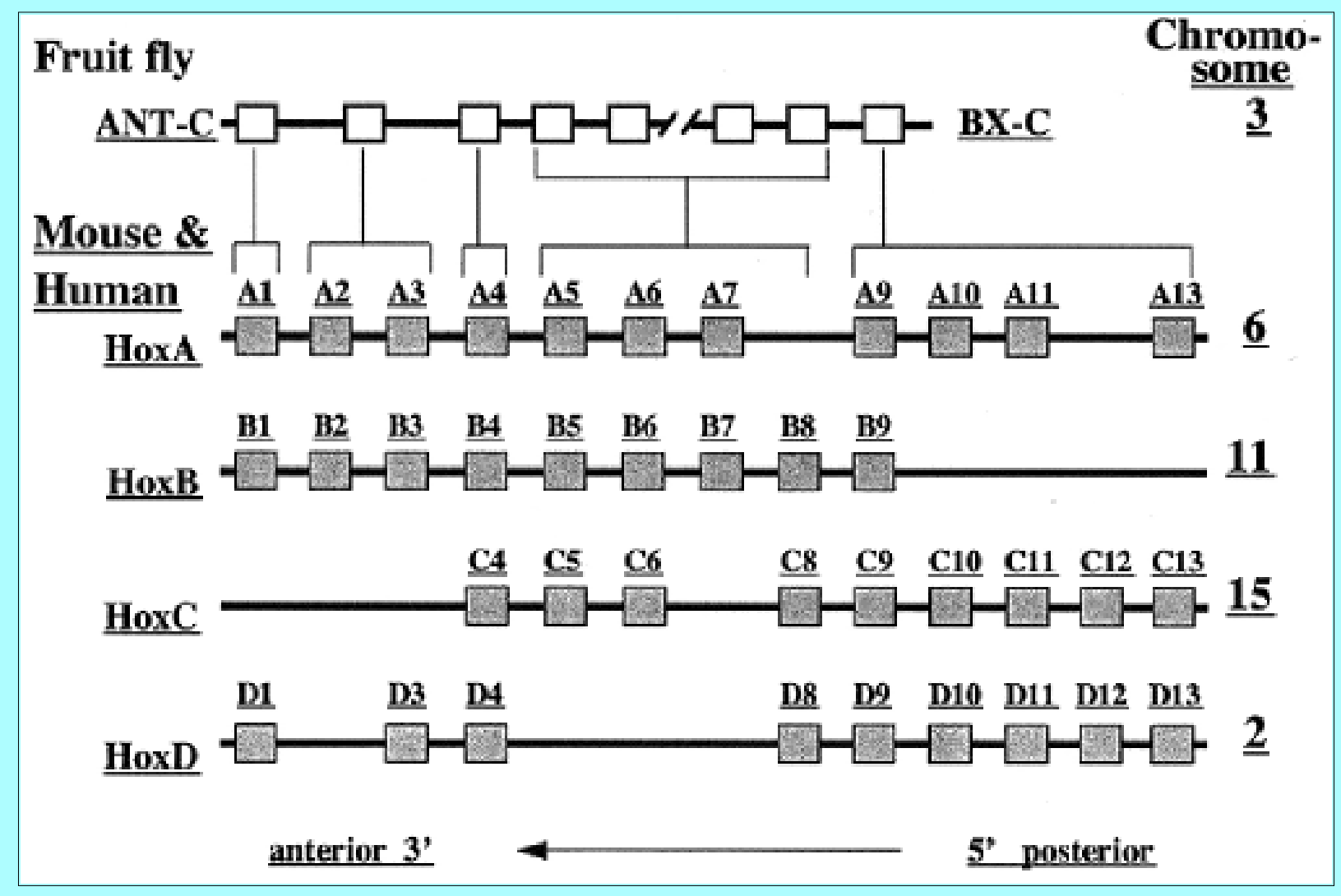

Fig. 7. Diagram illustrating the chromosomal organization of Hox genes in the mouse and human and their derivation from an ancestral complex equivalent to that found in Drosophila, the fruit fly. The salient points are 1) the presence of four clusters (A, B, C, and D) on different chromosomes, resulting 
from of cluster duplication during evolution; 2) the existence of so-called paralogous groups defined vertically across the clusters and consisting of up to four genes, each on a different chromosome, linked by common origin from an ancestral gene and identified by a common arabic numeral (thus, HoxA-4, B4, C4, and D4 are paralogues); 3) some paralogues have been lost during the course of evolution; 4) the expression of the genes along the anteroposterior axis of the embryo maps in a 1:1 fashion with their sequence within the cluster and along the $3^{\prime}$ to $5^{\prime}$ ( axis of the chromosome. Thus, HoxA-3, for example, has a more anterior limit to its expression domain than does HoxA-10.

Although their downstream target genes are as yet unknown, it is known that Hox genes are needed to establish correct positional specification within the craniocaudal sequence of somites (for a review, see references[14,23,31]). In situ hybridization analysis indicates that axial expression of Hox genes follows a general principle: the more 3' the position of a gene in the chromosomal cluster, the more anterior is its boundary of expression in the neural tube and the prevertebrae.[15] Mutations in Hox genes, and teratogen-induced disturbance of Hox gene expression, can both cause alterations of the number and identity of those cervical vertebrae that form at or near the anterior limit of their expression domain.[5,8,25,44,55] For instance, inactivation of homeobox-containing gene Hox-D3 results in mutant mice in which the atlas assimilates to the basiocciput.[7] Thus, by losing the function of a Hox gene, the first cervical vertebra is transformed into a more rostral identity, which is termed an "anterior homeotic transformation." Conversely, extension of an expression domain rostrally can transform structures into a more caudal identity, a phenomenon known as "posterior homeotic transformation." This is exemplified by the "gain-of-function" transgenic mutation of Hox-D4, whereby the occipital region of the skull is changed into cervical vertebral phenotypes, leaving the cervical spine itself unchanged[34] (Fig. 7). Given this sensitivity of the occipitocervical junction to perturbation by changes in Hox gene expression, such genetic changes might prove to be the underlying causes of malformations in this part of the human body. Thus, assimilation of the atlas into the occiput, detected in 19 of our 30 cases, can be interpreted as an anterior homeotic transformation. However, there was no evidence of multiple segmental fusions caudal to the craniovertebral junction in any of the experimental mutant mice. Therefore, although mutations in Hox genes or, perhaps, environmental disturbance of Hox gene expression (by teratogens) might be causes of occipital assimilation of C-1 in patients with KFS, it is unlikely that such mechanisms can be used to explain the extensive vertebral fusions observed.

\section{Vertebral Fusions and Pax Genes}

Another group of regulatory genes, the Pax genes are considered to be much stronger candidates for causing congenital vertebral fusions. They also possess a phylogenetically well-conserved DNA sequence called the "paired-box" and many of them contain the "homeobox" sequence as well. Like the homeobox, the paired-box also encodes DNA-binding domains, a typical feature of a regulatory protein.[4] This family, unlike the classic clustering of the Hox genes, consists of nine genes divided into four classes that are dispersed around the genome and are not clustered.[53,54] As Barinaga[2] and Read[46] have indicated, mutations in several Pax genes are now known to be causally involved in some major human birth defects, such as aniridia (PAX-6) and Waardenburg syndrome Types I and III (PAX-3). Human and murine Pax genes are expressed in diverse cell types, but all contribute to development of the early nervous system, except the members of the first class, Pax-1 and -9.[4,53,54]

These two genes (Pax-1 and -9) control segmentation of the somites and sclerotomes to establish intervertebral boundaries.[33] In particular, the Pax-1 gene has been found to be pivotal in the reorganization of the sclerotome.[11] Normally, signaling from the intact notochord and/or the floor plate of the neural tube (by signal proteins such as Sonic hedgehog; see Left-Right Asymmetrical Fusion) is necessary for the occurrence of sufficient Pax-1 gene expression in somites and in sclerotomes during primary segmentation, which, in turn, is required for the formation of the ventral parts of the vertebrae[30,60] (Fig. 8). During chondrification of the vertebrae, the Pax-1 gene is strongly expressed in the developing discs. This might be a late function of Pax-1 compared with the patterning of early sclerotome cells, but again it represents maintenance of the boundaries between axial skeletal elements. In this respect the Pax-1 gene acts like a "resegmentation gene."[60] 


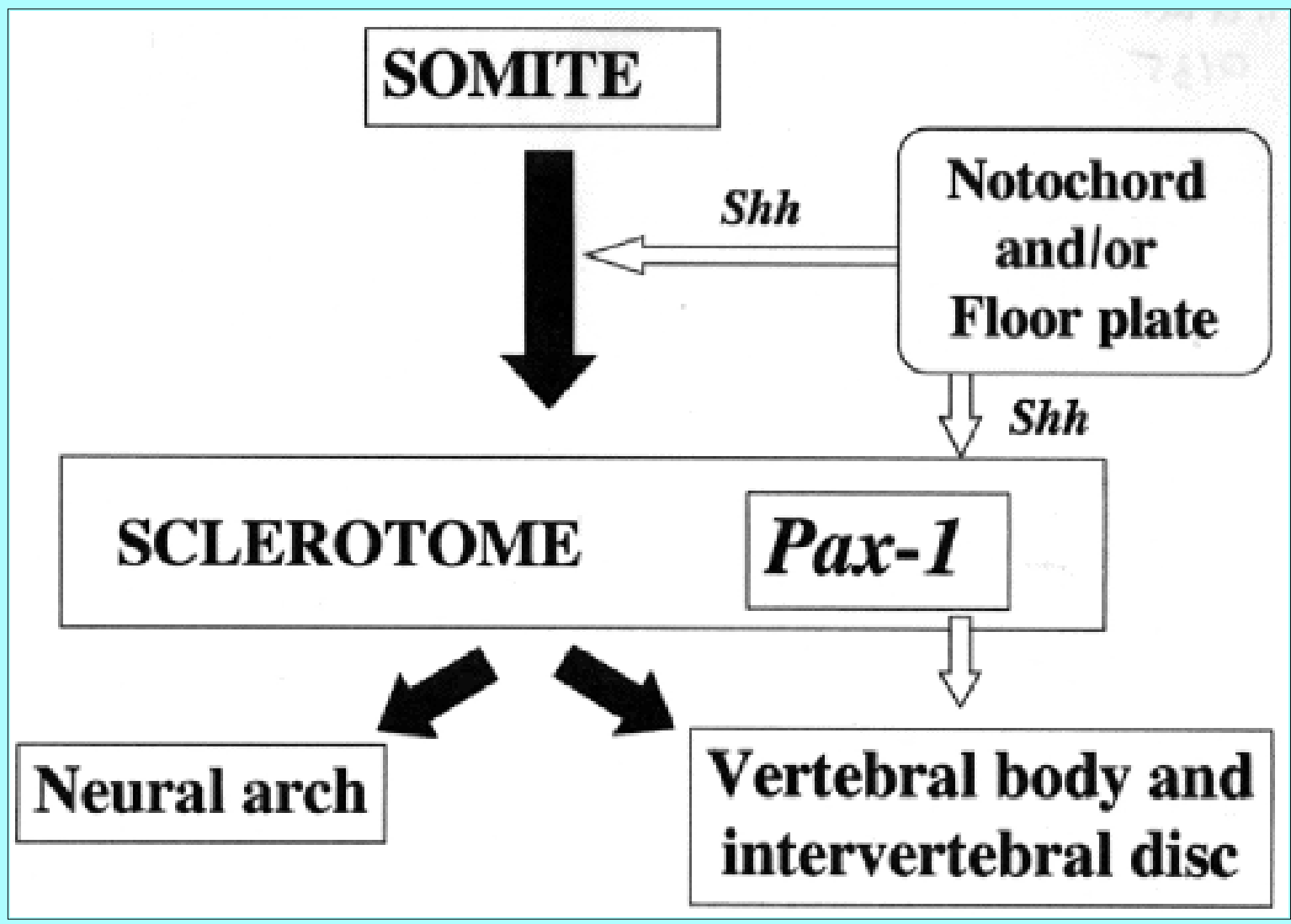

Fig. 8. Diagram depicting the range and sequence of tissue interactions that underlie the cell-signaling events necessary to build a vertebral body. Initially, expression of the regulatory gene, Pax-1, is involved in primary segmentation of the paraxial mesoderm into somites (not shown here; see text). Subsequently, a peptide signal encoded by the Shh gene, emanating from the notochord and the ventral floor plate of the neural tube, acts on the somite to induce sclerotome differentiation. The sclerotome itself then differentially expresses Pax-1, with expression ventrally reflecting the dorsoventral specification of each vertebra. Within this ventral expression domain of the sclerotomes, much more intense expression is demonstrated at those axial levels at which the intervertebral discs will form, and this appears to function in the resegmentation of the vertebrae (see text for further details).

Analysis of the undulated mutant mouse reveals a mutation within the Pax-1 paired-box domain that encodes the DNA-binding region of the protein; the phenotype displays a dysmorphic vertebral column in which vertebral bodies and intervertebral discs are fused, misshapen, or absent, and proximal regions of the ribs are either missing or malformed.[4,60] Mutation at another locus (Danforth's short-tail) causes early degeneration of the notochord, which results in downregulation of Pax-1 in the sclerotome, and produces a similar disruption to the ventral aspects of the vertebral primordia.[31] Perhaps not surprisingly, PAX-1, the human homologue,[1] is expressed in the human vertebral column at least as early as 7 weeks of development, in the intervertebral disc primordia.[53] Furthermore, the experimental use of antisense strategies to inactivate Pax-1 messenger RNA during somitogenesis produces fusions,[52] further supporting the idea that Pax-1 is critical in the development of a properly segmented vertebral column. As with the Hox homeoproteins, the identity of the downstream target genes, that is, those in which expression is regulated by the Pax proteins, is largely unknown.

Thus, we can conclude that impaired or reduced PAX-1 expression, for whatever reason, will result in local or widespread atypical fusion between the sclerotomal primordia. The phenotypic consequence will be vertebral fusions, even through the craniovertebral junction, which is sometimes observed clinically. Although the likelihood that mutation in the PAX-1 gene is responsible for the KFS phenotype has been considered,[53] it has not been rigorously investigated to date. Whatever level in the signaling cascade is affected, it is by no means a foregone conclusion that the original cause is necessarily always genetic. Given that only in a small minority of patients with KFS is there strong evidence of a genetic basis[6,21] (in only three patients in this series was there evidence of a 
positive family history for vertebral fusions), many of these clinical cases may simply reflect a nongenetic disruption (such as by teratogens) during that window of development in which crucial morphogenetic events are taking place along the axis of the embryo. The localization and the extent of the congenital anomaly to, and along, a particular region of the axis would thus reflect the timing and duration, respectively, of the teratogenic insult.

We believe that these phenomena may be, at least in part, responsible for the formation of subaxial fusions and for the two cases in which axial fusions involved the clivus.

\section{Left-Right Asymmetrical Fusion}

In previous reports on fusion patterns the investigators have mainly concentrated on the difference between ventral and dorsal fusion patterns, that is, fusion of vertebral bodies or laminae. Not much has been written about the left-right asymmetrical fusion, and yet the incidence was nearly $60 \%$ in our series. Von Torklus and Gehle,[59] in describing types of unilaterally disturbed segmentation in the atlantoaxial region, assumed that they resulted from an early embryonic disturbance of the notochord. Other investigators have mentioned asymmetrical fusion between the two sides of occipitalized C-1, which was demonstrated in seven of our 19 patients in whom C-1 assimilation was found, but they did not provide any further explanation.[13,24,41]

Research on the regulation of normally occurring left-right asymmetric organs (such as the development of the heart from the heart tube) in vertebrates has revealed that the responsible genes are expressed during and immediately after gastrulation[32,64] and led to speculation that the left-right axial information is contained in the extracellular matrix early in development.[63] During gastrulation the notochordal process originates from the primitive node, and cells migrate through the primitive streak to form the mesoderm. It has been proposed that an intact notochord is necessary to induce sclerotome development, and a signal protein, encoded by the Sonic hedgehog (Shh) gene and secreted by both the notochord and ventral floor plate of the neural tube, serves to induce Pax-1 expression and sclerotome differentiation in the paraxial mesoderm[16,17] (Fig. 8). The same Shh gene is strongly expressed in the primitive node, suggesting that this gene also plays a key role during gastrulation. Additionally, the Shh gene is expressed in a left-right asymmetric pattern during gastrulation, which makes it a candidate agent that normally establishes left-right differences.[32]

Injury to the primitive node/primitive streak complex, reducing the number of paraxial mesodermal cells, could impair the formation of the skeletal-neural axis of the embryo.[35] This impairment, together with an insufficiency of notochord-derived signal that is necessary to maintain Pax-1 expression in the sclerotome and primitive node-derived signal for symmetrical-asymmetrical patterning (both can be mediated by Shh gene product as discussed previously), may lead to both faulty segmentation and disturbed symmetry, which eventually cause asymmetrical fusion patterns. Faulty signaling across the embryonic midline might also play a role because asymmetrical fusions were often associated with split vertebral bodies or hemivertebrae.

\section{Left-Right Ossification and Progressive Bone Fusion}

Although recognized clinically, it is rarely stated explicitly that the fused vertebral bodies are in fact flattened and wide. Additionally, in a young child the extent of a segmentation failure cannot be truly appreciated because the ossification of the vertebral bodies is incomplete early on, and therefore the final pattern of fusion is not obvious until early adolescence. $[3,22,57]$ In seven of our cases it was obvious that the ultimate shape of the fused vertebral bodies and the chondrified vertebral centra of the human embryo were similar. The small anteroposterior diameter, the wide vertebral bodies, and midsagittal division or groove are all normal features at the chondrification stage of vertebral development (6-10 weeks postfertilization)[10] (Fig. 9). This, together with the observation that bone fusion progresses with age, suggests that the fusions occur before or during the chondrification stage. Thus, whereas the fusion pattern is established early, it will only become manifest with ossification in the preexisting cartilaginous fusions. 


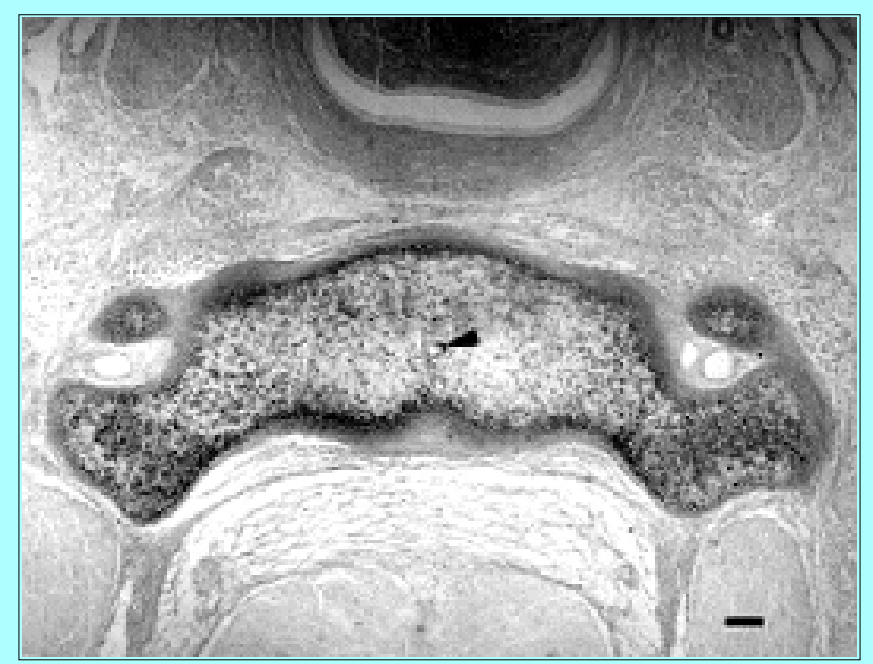

Fig. 9. Photomicrograph showing a transverse histological section of cartilaginous cervical vertebra of an 8-week-old human embryo with small anteroposterior diameter, wide and narrow shape, midsagittal groove, and the area of the notochord (arrowhead). Note similarities to the axial view of a fused vertebral body (see Fig. 5). Alcian-blue stain, magnification bar represents $100 \mu \mathrm{m}$.

\section{CONCLUSIONS}

The observed radiological patterns in the present series of patients with KFS have led us to postulate the following hypotheses. 1) Homeotic transformation caused by mutations or disturbed expression of Hox genes is a possible factor for C-1 assimilation. 2) Notochordal defects and/or signaling problems, which result in reduced or impaired Pax-1 gene expression, are likely to be among the several causes of vertebral fusions. 3) This, together with asymmetrically distributed paraxial mesodermal cells and a possible lack of cellular communication across the embryonic midline, could generate the frequent left-right asymmetrical fusions. 4) The wide and flattened shape of the fused vertebral bodies, their resemblance to the embryonic cartilaginous vertebrae, and progressive bone fusion with age suggest that the fusions simply occur before or, at the latest, during chondrification of vertebrae, and bone fusion simply occurs as a result of ossification through the preexisting cartilaginous fusion bars (Table 2).

Although speculative, these conclusions clearly indicate the potential value of integrating modern molecular knowledge, emerging from contemporary developmental biology, with problems of clinical dysmorphology and its interpretation. Although the role of Hox and Pax genes in human vertebral dysmorphogenesis remains to be fully elucidated, we nevertheless contend that molecular and genetic perspectives such as these must be integrated with the traditional clinical and, indeed, anthropological interpretations of causality.

\section{Acknowledgments}

The authors would like to thank Dr. Christine Hall for her valuable opinion in reviewing the manuscript and Mr. Richard D. Hayward, Mr. Hilali Noordeen, and Mr. Andrew O. Ransford for allowing us to include their cases in the study.

Professor Peter V. Thorogood, who was head of the Developmental Biology Unit, died tragically in a climbing accident in Switzerland in August 1998. His many original molecular genetic observations have changed our perception of spinal development.

\section{References}

1. Balling R: The undulated mouse and the development of the vertebral column. Is there a human $P A X-1$ homologue? Clin Dysmorphol 3:185-191, 1994

2. Barinaga M: Focusing on the eyeless gene. Science 267:1766-1767, 1995 
3. Bland JH: Congenital anomalies, in Bland JH (ed): Disorders of the Cervical Spine. Diagnosis and Medical Management. London: WB Saunders, 1987, pp 303-306

4. Chalepakis G, Fritsch R, Fickenscher H, et al: The molecular basis of the undulated/Pax-1 mutation. Cell 66:873-884, 1991

5. Charité J, de Graaff W, Shen S, et al: Ectopic expression of Hoxb-8 causes duplication of the ZPA in the forelimb and homeotic transformation of axial structures. Cell 78:589-601, 1994

6. Clarke RA, Kearsley JH, Walsh DA: Patterned expression in familial Klippel-Feil syndrome. Teratology 53:152-157, 1996

7. Condie BG, Capecchi MR: Mice homozygous for a targeted disruption of Hoxd-3 (Hox-4.1) exhibit anterior transformations of the first and second cervical vertebrae, the atlas and the axis. Development 119:579-595, 1993

8. Condie BG, Capecchi MR: Mice with targeted disruptions in the paralogous genes hoxa-3 and hoxd-3 reveal synergistic interactions. Nature 370:304-307, 1994

9. David KM, Copp AJ, Stevens JM, et al: Split cervical spinal cord with Klippel-Feil syndrome: seven cases. Brain 119:1859-1872, 1996

10. David KM, McLachlan JC, Aiton JF, et al: Cartilaginous development of the human craniovertebral junction as visualised by a new three-dimensional computer reconstruction technique. J Anat 192:269-277, 1998

11. Deutsch U, Dressler GR, Gruss P: Pax-1, a member of a paired box homologous murine gene family, is expressed in segmented structures during development. Cell 53:617-625, 1988

12. Diekmann-Guiroy B, Huang PS: Klippel-Feil syndrome in association with a craniocervical dermoid cyst presenting as aseptic meningitis in an adult: case report. Neurosurgery 25:652-655, 1989

13. Dietemann JL, Doyon D, Aubin ML, et al: Cervico-occipital junction: normal and pathological aspects, in Menalfe C (ed): Imaging of the Spine and Spinal Cord. New York: Raven Press, 1992, p 719

14. Dietrich S, Kessel M: The vertebral column, in Thorogood P (ed): Embryos, Genes and Birth Defects. Chichester: John Wiley and Sons, 1997, pp 281-302

15. Duboule D, Dollé P: The structural and functional organisation of the murine $H O X$ gene family resembles that of Drosophila homeotic genes. EMBO J 8:1497-1505, 1989

16. Ebensperger C, Wilting J, Brand-Saberi B, et al: Pax-1, a regulator of sclerotome development is induced by notochord and floor plate signals in avian embryos. Anat Embryol 191:297-310, 1995

17. Fan CM, Porter JA, Chiang C, et al: Long-range sclerotome induction by sonic hedgehog: direct role of the amino-terminal cleavage product and modulation by the cyclic AMP signalling pathway. Cell 81:457-465, 1995

18. Gruss P, Kessel M: Axial specification in higher vertebrates. Curr Opin Genet Dev 1:204-210, 1991

19. Gumerlock MK, Spollen LE, Nelson MJ, et al: Cervical neurenteic fistula causing recurrent meningitis in Klippel-Feil sequence: case report and literature review. Pediatr Infect Dis J 10:532-535, 1991

20. Gunderson $\mathrm{CH}$, Greenspan RH, Glaser GH, et al: The Klippel-Feil syndrome: genetic and clinical reevaluation of cervical fusion. Medicine 46:491-512, 1967

21. Gunderson CH, Solitare GB: Mirror movements in patients with the Klippel-Feil syndrome. Neuropathologic observations. Arch Neurol 18:675-679, 1968

22. Hensinger RN, Lang JE, MacEwen GD: Klippel-Feil syndrome. A constellation of associated anomalies. J 
Bone Joint Surg (Am) 56:1246-1253, 1974

23. Hunt P, Krumlauf R: Hox codes and positional specification in vertebrate embryonic axes. Annu Rev Cell Biol 8:227-256, 1992

24. Jones DN, Davies R, Sage MR: Assimilation of the atlas with associated syringomyelia and Chiari 1 malformation (Klippel-Feil type 2). Australas Radiol 36:339-342, 1992

25. Kessel M, Balling R, Gruss P: Variations of cervical vertebrae after expression of a Hox-1.1 transgene in mice. Cell 61:301-308, 1990

26. Kessel M, Gruss P: Homeotic transformation of murine vertebrae and concomitant alteration of Hox codes induced by retinoic acid. Cell 67:1-20, 1991

27. Keynes RJ, Stern C: Mechanisms of vertebrate segmentation. Development 103:413-429, 1988

28. Kieny M, Mauger A, Sengel P: Early regionalization of the somitic mesoderm as studied by the development of the axial skeleton of the chick embryo. Dev Biol 28:142-161, 1972

29. Klippel M, Feil A: Un cas d'absence des vertebres cervicales. Avec cage thoracique remontant jusqu'a la base du crane (cage thoracique cervicale). Nouv Iconog Salpetriere 25:223-250, 1912

30. Koseki H, Wallin J, Wilting J, et al: A role for Pax-1 as a mediator of notochordal signals during the dorsoventral specification of vertebrae. Development 119:649-660, 1993

31. Krumlauf R: Hox genes in vertebrate development. Cell 78:191-201, 1994

32. Levin M, Johnson RL, Stern C, et al: A molecular pathway determining left-right asymmetry in chick embryogenesis. Cell 82:803-814, 1995

33. Love JM, Tuan RS: Pair-rule gene expression in the somitic stage chick embryo: association with somite segmentation and border formation. Differentiation 54:73-83, 1993

34. Lufkin T, Mark M, Hart CP, et al: Homeotic transformation of the occipital bones of the skull by ectopic expression of a homeobox gene. Nature 359:835-841, 1992

35. Marín-Padilla M: Cephalic axial skeletal-neural dysraphic disorders: embryology and pathology. Can J Neurol Sci 18:153-169, 1991

36. Müller F, O'Rahilly R: Occipitocervical segmentation in staged human embryos. J Anat 185:251-258, 1994

37. Nagib MG, Maxwell RE, Chou SN: Identification and management of high-risk patients with Klippel-Feil syndrome. J Neurosurg 61:523-530, 1984

38. Nagib MG, Maxwell RE, Chou SN: Klippel-Feil syndrome in children: clinical features and management. Childs Nerv Syst 1:255-263, 1985

39. Nguyen VD, Tyrrel R: Klippel-Feil syndrome: patterns of bony fusion and wasp-waist sign. Skeletal Radiol 22:519-523, 1993

40. O'Rahilly R, Meyer DB: The timing and sequence of events in the development of the human vertebral column during the embryonic period proper. Anat Embryol 157:167-176, 1979

41. Penning L: Congenital disorders, in Penning L (ed): Functional Pathology of the Cervical Spine. Amsterdam: Excerpta Medica, 1968, p 76

42. Pizzutillo PD, Woods M, Nicholson L, et al: Risk factors in Klippel-Feil syndrome. Spine 19:2110-2116, 1994 
43. Quiring R, Walldorf U, Kloter U, et al: Homology of the eyeless gene of Drosophila to the Small eye gene in mice and Aniridia in humans. Science 265:785-789, 1994

44. Ramírez-Solis R, Zheng H, Whiting J, et al: Hoxb-4 (Hox-2.6) mutant mice show homeotic transformation of a cervical vertebra and defects in the closure of the sternal rudiments. Cell 73:279-294, 1993

45. Ramsey J, Bliznak J: Klippel-Feil syndrome with renal agenesis and other anomalies. AJR 113:460-463, 1971

46. Read AP: Pax genes--paired feet in three camps. Nat Genet 9:333-334, 1995

47. Roberts PA: A case of intracranial dermoid cyst associated with the Klippel-Feil deformity and recurrent meningitis. Arch Dis Child 33:222-225, 1958

48. Rock JP, Spickler EM: Anomalous rib presenting as cervical myelopathy: a previously unreported variant of Klippel-Feil syndrome. Case report. J Neurosurg 75:465-467, 1991

49. Schilgen M, Loeser H: Klippel-Feil anomaly combined with fetal alcohol syndrome. Eur Spine J 3:289-290, 1994

50. Schott GD, Wyke MA: Congenital mirror movements. J Neurol Neurosurg Psychiatry 44:586-599, 1981

51. Smith CA, Tuan R: Functional involvement of $P a x-1$ in somite development: somite dysmorphogenesis in chick embryos treated with Pax-1 paired-box antisense oligonucleotide. Teratology 52:333-345, 1995

52. Smith CA, Tuan R: Human $P A X$ gene expression and development of the vertebral column. Clin Orthop 302:241-250, 1994

53. Strachan T, Read AP: PAX genes. Curr Opin Genet Dev 4:427-438, 1994

54. Stuart ET, Kioussi C, Gruss P: Mammalian Pax genes. Annu Rev Genet 27:219-236, 1993

55. Subramanian V, Meyer BI, Gruss P: Disruption of the murine homeobox gene $C d x l$ affects axial skeletal identities by altering the mesodermal expression domains of Hox genes. Cell 83:641-653, 1995

56. Thorogood P (ed): Embryos, Genes and Birth Defects. Chichester: John Wiley \& Sons, 1997

57. Ulmer JL, Elster AD, Ginsberg LE, et al: Klippel-Feil syndrome: CT and MR of acquired and congenital abnormalities of cervical spine and cord. J Comput Assist Tomogr 17:215-224, 1993

58. Verbout AJ: The development of the vertebral column. Adv Anat Embryol Cell Biol 90:1-122, 1985

59. Von Torklus D, Gehle W: The Upper Cervical Spine. Regional Anatomy, Pathology and Traumatology. A Systematic Radiological Atlas and Textbook. New York: Grune \& Stratton, 1972, pp 45-63

60. Wallin J, Wilting J, Koseki H, et al: The role of Pax-1 in axial skeleton development. Development 120:1109-1121, 1994

61. Whiting DM, Chou SM, Lanzieri CF, et al: Cervical neurenteric cyst associated with Klippel-Feil syndrome: a case report and review of the literature. Clin Neuropathol 10:285-290, 1991

62. Whittle IR, Besser M: Congenital neural abnormalities presenting with mirror movements in a patient with Klippel-Feil syndrome. Case report. J Neurosurg 59:891-894, 1983

63. Yost HJ: Regulation of vertebrate left-right asymmetries by extracellular matrix. Nature 357:158-161, 1992

64. Yost HJ: Vertebrate left-right development. Cell 82:689-692, 1995

Manuscript received April 21, 1999. 
Accepted in final form May 6, 1999.

Dr. Karoly M. David's work was performed while he was a research fellow in the Department of Surgical Neurology, at the National Hospital for Neurology and Neurosurgery. He also received support from the Department of Neurosurgery, University of Pécs Medical School, Hungary.

Address reprint requests to: Mr. H. Alan Crockard, F.R.C.S., Consultant Neurosurgeon, Department of Surgical Neurology, The National Hospital for Neurology and Neurosurgery, Queen Square, London WC1N 3BG, United Kingdom. email: A.Crockard@ion.ucl.ac.uk. 